\title{
Mental Health in the UK Police Force: a Qualitative Investigation into the Stigma with Mental IIIness
}

\author{
Ann-Marie Edwards ${ }^{1} \cdot$ Yasuhiro Kotera ${ }^{2}$
}

Published online: 15 January 2020

(C) The Author(s) 2020

\begin{abstract}
Police work is a high-risk profession that can cause mental health conditions. With increasing sickness levels and falling police numbers, it is essential prompt mental health treatment be implemented. The study aims to explore institutional negativity and stigma in the police force towards mental ill health. Semi-structured interviews attended by five police officers with thematic analysis captured (i) police culture, (ii) the stigma of mental illness, (iii) disclosure of mental illness and (iv) breaking down barriers. Findings indicate police culture and attitudes to mental health may contribute to the causes of psychological illness, rather than the nature of the job itself. Increased education and awareness surrounding mental health have been shown to be fundamental in how an officer reacts to stress, but change is needed at a managerial level. Future research needs to explore the effects of mental health stigma on ethnicity and gender in the police force.
\end{abstract}

Keywords Police culture - Mental illness · Mental health stigma - Discussing mental health · Mental health awareness

A police officer is responsible for the prevention and detection of criminal activity, whilst maintaining public order (Myhill and Quinton 2011). Sickness absence has become a growing concern in the UK police force, employing approximately 130,000 police officers (Hargreaves et al. 2018): with half of officers taking sickness leave for mental health-related illnesses in the last 5 years (Police Firearms Officer Association 2017). This is not limited to the UK police force. For example, an Australian study reported a higher prevalence of mental illness among the police and emergency services than other professions (Harman 2019). Likewise, in Canada, mental illness is widespread among police officers; high proportions of them reported having suicidal ideation (10\% during the past year, $28 \%$ in lifetime), planned suicide (4\%

Ann-Marie Edwards

a.edwards18@unimail.derby.ac.uk

1 University of Derby, Kedleston Road, Derby DE22 1GB, UK

2 Online Counselling and Psychotherapy, University of Derby, Kedleston Road, Derby DE22 1GB, UK 
during the past year, $13 \%$ in lifetime), and attempted suicide ( $0.4 \%$ during the past year, $5 \%$ in lifetime) (Carleton et al. 2018; The Centre for Addiction and Mental Health (CAMH) 2018). Mental wellbeing of police officers is a cause for concern in many countries, highlighting the need for further study.

Generally, mental illness in the workplace results in a significant economic burden (LaMontagne et al. 2014), due to long-term sickness absence (Thomas et al. 2016): 16 million days are estimated to be lost annually due to mental health issues such as stress, depression and anxiety (Office for National Statistics 2017).

Recent research has identified policing as a hazardous and stressful occupation (Deschamps et al. 2003; Liberman et al. 2002; Tuckey et al. 2012). The consequences of organisational stressors and the high-risk nature of frontline duty mean officers are at greater risk of developing psychological illnesses (Habersaat et al. 2015). Cumulative exposure to a number of potentially traumatic situations is an integral part of operational policing (Tuckey et al. 2012), and thought to be a predictor for the development of post-traumatic stress disorders (PTSDs) (Marchand et al. 2015; Marmar et al. 2006), depression, anxiety and other stressrelated conditions (Husain 2014). If left untreated, mental ill health has the potential to adversely affect workplace performance and future career prospects (Heffren and Hausdorf 2016). The cost of stress-related illnesses for officers is viewed in the context of individual mortality and morbidity, culminating in reduced productivity, sick leave and premature retirement (Collins and Gibbs 2003; Summerfield 2011). As criminality on our streets increases, unpredictable events that the police encounter remain commonplace (Marchand et al. 2015). As such, there is a higher prevalence of stress-related illnesses in the police force than in the general public (Soomro and Yanos 2018).

It is vital for officers to look after their mental health; however, research by mental health charity Mind (2013) suggests that emergency services personnel are less likely to seek help for mental health conditions. Officers may resist disclosing their mental ill health for fear of stigma and negative reactions from colleagues (Bullock and Garland 2018; Kurtz 2008). Internal stigma, where the police stigmatise each other because of mental health problems, is pervasive in the police force and was identified as playing an essential role in influencing individual reactions to stress (Stuart 2017). It plays a significant role in the way a person responds to psychological distress and has been noted as one of the main reasons why officers avoid seeking help (Stuart 2017).

Much has been reported about workplace stress (Alexopoulos et al. 2014; Kotera et al. 2018a; Morash et al. 2006; Violanti et al. 2016), and in regard to policing, a variety of research within the last 20 years has focussed on law enforcement's perception of mental health in the community (Desmarais et al. 2014; Lamb et al. 2002; Soomro and Yanos 2018; Watson et al. 2014; Wood et al. 2017); however, the occupational psychological distress of police officers has received little attention in the research literature. Frequent exposure to operational stressors has the potential to significantly affect the psychological functioning of police officers (Marchand et al. 2015). Given the critical role of police work, it is crucial to understand the psychological strain this puts on officers. Increasing mental health awareness and education at an organisational level is essential in helping to alleviate the psychological symptoms derived from their occupation (Randall and Buys 2013). The experiences officers face at an operational and organisational level is decisive in determining their mental wellbeing (Deschamps et al. 2003).

Deschênes et al. (2018) reported that the culture and style of leadership within the police force has more influence in determining an officer's mental wellbeing, rather than the actual 
nature of the job itself. Access to mental health support is provided through occupational health services by delivering one-to-one counselling. In contrast, despite access to those services, officers continue to face considerable psychological distress as a consequence of the pressures they encounter at an institutional level (Fox et al. 2012).

Regrettably, due to the lack of mental health training within police forces (Cummings and Jones 2010), additional training is required in order to change attitudes towards mental health (Booth et al. 2017; Soomro and Yanos 2018). Addressing these attitudes starts at a managerial level (Bell and Eski 2016). Line managers need education on how to identify the triggers and warning signs of mental health conditions among their officers. Preventative measures (Hayday et al. 2007), early intervention (Tuohy et al. 2005), together with prompt treatment from mental health services will help to ensure that periods of short absence do not turn into long-term sickness absence (Summerfield 2011).

The updated hypothesis extended from the original version of labelling theory (Scheff 1966) called into question the significance of stigma and stereotyping of individuals and the consequent discrimination, loss of socioeconomic status, low self-esteem and increased symptoms (Markowitz 2014). The modified labelling theory (Link et al. 1989) argued that labelling negatively influences mental wellbeing, even when it is not specifically the cause of mental disorders; labelling can make individuals feel isolated and discriminated, damaging their coping and social bonding skills (Link et al. 1989). Research in the field of modified labelling theory indicates that stigma plays an important part in labelling (Markowitz 2014). Accordingly, the present study aims to examine mental wellbeing of UK police officers, focussing on police culture and the attitudes towards the mental health of police officers.

\section{Sickness Absence}

Given the increase in sickness absence for stress-related conditions (Police Firearms Officers Association 2017), the mental wellbeing of police officers has become an increasingly important topic. A study by the Police Federation in 2016 involving 17,000 officers found that mental wellbeing among police officers was considerably poorer than that of the general population, with 39\% needing help for mental ill health (Houdmont and Elliott-Davies 2016). Furthermore, socioeconomic factors such as increased budget restrictions, higher levels of crime and falling police numbers are placing more pressure on officers (Police Federation 2020). If this trend continues, it will likely create a more significant mental health crisis in the police force.

\section{Police Culture and Mental Illness}

Society has a stereotypical view of mental illness, and law enforcement is no exception. The culture of policing makes it difficult for officers to disclose mental illness, many of whom will subsequently suffer in silence. This culture of dominance and masculinity (Evans et al. 2013) as well as emotional self-control (Bell and Eski 2016) and stigma make officers resistant to help-seeking. Displays of emotional responses to work-related stressors are often regarded within police culture as a sign of weakness and not comparable with the masculine perception of policing (Kurtz 2008). 


\section{Stigma of Mental IIIness}

Stigma is a label given to those who may have a personal or physical characteristic that distinguishes them from others (Wester et al. 2010). This often places individuals into a stereotypical group, consequently leading to discrimination and isolation. Labels commonly associated with mental ill health not only have the potential to stigmatise, but to alienate individuals as well. The social stigma attached to mental ill health, and the discrimination people face, makes it difficult for them to seek any psychological intervention (Kotera et al. 2018b; Kotera \& Ting, 2019). Furthermore, officers who experience increased stigma tend to have negative opinions about seeking psychological support (Soomro and Yanos 2018). Unsurprisingly, police officers suffering from mental ill health are seen as a marginalised community within the police service (Bell and Eski 2016). The decision not to disclose mental health conditions can adversely affect the wellbeing of officers (Stuart 2017). It is important to consider mental health stigma with regard to police work and the probable risks of disclosure.

The present study used a qualitative approach, attempting to explore the first-hand experience of police officers. Although police work is regarded as a high-risk occupation for the development of mental health conditions (Burke 1998), there is still a lack of empirical evidence to support these claims (Van Der Velden et al. 2013). Likewise, understanding of research into the attitudes of the police force towards officers with mental health problems remains limited (Deschênes et al. 2018).

\section{Methodology}

\section{Participants}

Five participants were recruited through a referral from a charity, personal network, police forum and contact from within the police force. Participants were suitable if they were (i) over the age of 18; (ii) serving officers with mental ill health, or who had been on sick leave due to mental ill health or have left the police force due to a mental health condition and (iii) proficient in English. Participants who do not speak English, have not been diagnosed with a mental health condition or have had exposure to a recent violent crime or traumatic event which has impacted on their mental health were excluded from the study.

Appendix 1 summarises the participant demographic information. Participants consisted of four males and one female (three retired and two serving officers). The mean age was 52 years (range 43-62) old. Four participants described their ethnicity as white British, and one retired officer only disclosed his ethnicity as British. Three participants were currently married, one divorced and one single. The mean length of the time in the police force was 24 years (range 18-30 years). Officer rank included police constable $(N=2)$ and sergeant $(N=3)$. All participants had experienced a variety of mental ill health conditions such as stress, anxiety, depression and PTSD. As all participants have experienced some form of mental ill health; it was important to put measures in place to protect them should the interview cause them any psychological harm. The researcher was responsible for ensuring participant privacy and confidentiality and providing details of who to contact should the interview cause the participant any undue distress. 


\section{Semi-Structured Interviews}

Semi-structured interviews were conducted to attain an in-depth understanding of the participants' lived experiences (Sofaer 1999). The interview was guided by open-ended questioning, encouraging meaningful discussion (Weller et al. 2018) about each participant's accounts of mental health awareness in the police force. The question order was determined by the flow of the interview. Interviews began with a brief overview of the participant's career in policing, together with the reasons for the onset of their mental health conditions. All aspects of information and information-seeking were explored. Interviews were audio-recorded and lasted for an hour on average. Recordings were transcribed verbatim and analysed.

\section{Materials}

Participants were provided with a formal invitation to participate, an information sheet and consent form outlining the procedure, benefits and risks of participating. This included an explanation of how to acquire the results of the research, details of mental health services, voluntary participation, how to withdraw and contact information for the researchers.

\section{Procedure}

After informed consent was granted, the researcher commenced the interviews using the proposed interview schedule as a basis for open-ended questioning (Appendix 2). On completion of each interview, all participants were thanked for their time, and a formal debrief was sent to each participant by e-mail which reiterated the purpose of the study, details on their right to withdraw and contact information of mental health services, along with contact details of the researchers.

\section{Qualitative Data Analysis}

Data were analysed using the thematic analysis (Braun and Clarke 2006), an approach used for identifying, analysing and reporting themes found in qualitative data. The purpose of using thematic analysis in the present study is that this method is regarded most appropriate to investigate into under-researched areas, while still providing high research rigour (Braun and Clarke 2006). Thematic analysis identifies patterns in the dataset to extract trustworthy and insightful findings (Nowell et al. 2017). In line with the recent updates on thematic analysis (Clarke and Braun 2018), the researchers of this study actively engaged with the personal accounts of participants, and reported findings in a straightforward manner.

The interviews were transcribed, read and re-read until the researchers became fully immersed in the dataset. This method of familiarisation set the foundation for the subsequent data analysis. Having become familiar with the dataset, a list of initial codes was manually generated to identify keywords. The extracted data were again re-read in order to double-check the initial codes. During this process, some codes were discarded due to inconsistencies with the dataset (Identifying). A slight overlap was noted in regard to the subtheme 'support'; however, it was felt that the topic warranted inclusion in the two main themes: 'the stigma of mental health' and 'breaking down barriers.' Names for each theme were then finalised, providing each theme with names and explicit descriptions that were necessary to capture the essence of every theme (Analysing). Finally, the data were transformed into a written report, supported by empirical evidence (Reporting). 


\section{Results}

The analysis identified four themes: police culture, the stigma of mental health, disclosing mental illness and breaking down barriers (Appendix 3).

\section{Theme 1: Police Culture}

A recurrent theme throughout the interviews was a sense among participants that the culture within policing often inhibits any open and honest discussion around mental health issues with senior management and colleagues. Existing research has acknowledged that police culture influences work-related stress (Deschênes et al. 2018). Additionally, it can easily isolate officers from important support mechanisms, and in so doing, heightening the likelihood of developing a mental illness (Tuckey et al. 2012).

\section{Subtheme 1.1: Macho Culture}

In all cases, participants reported operational and organisational stressors had affected them to some degree. Policing has long been stereotyped and perceived as masculine. This 'macho' culture means many officers do not feel comfortable about disclosing mental illness and will likely avoid seeking support for mental health issues as a result of the widespread belief that their masculinity might be called into question (Bell and Eski 2016; Garbarino et al. 2013; Wester et al. 2010).

I've seen too many people, particularly the police, adopt the macho attitude, go pop and some of them are dead, some of them become alcoholics, some had to leave the job because they plunge from one crisis to the next. (Participant 3).

Emotional responses to psychological illnesses resulting from work-related stressors are considered as a sign of weakness and not encouraged within law enforcement (Garbarino et al. 2013). These opinions undoubtedly add to the feelings of shame experienced by many officers. One individual used the analogy of soldiers who had suffered from shellshock in World War I and were viewed by colleagues as cowards and malingerers (Pols and Oak 2007).

It's a bit like the shell-shocked veterans in World War 1, being branded as cowards and shot, you know, they're cowards. (Participant 4).

Participant responses were consistent with research reporting that policing encourages masculinity, self-reliance and emotional control, which in turn has a negative impact on help-seeking behaviour (Johnson 2016).

\section{Subtheme 1.2: Emotional Response Is a Sign of Weakness}

Because police officers are typically regarded as self-reliant, tough and aggressive (Soomro and Yanos 2018), any display of emotional response to work stressors will risk them being stigmatised for appearing weak (Kurtz 2008). Any vulnerability may cause colleagues to distrust their ability (Heffren and Hausdorf 2016). This negative mindset from colleagues and line management leads to the individual feeling uncomfortable in sharing any psychological suffering for fear of the repercussions, resulting in many continuing to suffer in silence, thus preventing early psychological intervention (Garbarino et al. 2013). 
You've got to be able to go out and unload to somebody, who might not necessarily know anything about the police. (Participant 3).

One officer did not realise there was a problem but acknowledged there must have been a gradual decline in her mental health over a significant period time.

I didn't recognise it as what it was; I just thought I was grumpy...you don't see them creeping up, and in the end, the thing that tips you over the edge, the thing that makes your bottle overflow if you like can be something quite small because you've got used to dealing with stuff. (Participant 5).

Talking about mental health is crucial in helping to share experiences and normalise feelings.

I would just talk about what happened to me, and for me that makes me feel better. (Participant 4).

Officers will typically suppress any emotion by adopting a 'get on with it' kind of attitude; however, it can adversely affect the psychological wellbeing of even the most resilient of police officers, taking a physical and mental toll upon the individual if it remains unrecognised and undiagnosed (Hayday et al. 2007; Karaffa and Koch 2015). Regrettably, police culture often inhibits discussion around psychological illnesses (Bell and Eski 2016). As such, avoidance is common (Stuart 2017).

You sort of bottled it up for years, you just kept going because I had a young family to support. I had to earn the money and the overtime and one thing and another. I think I got to a point where I'd just had enough. (Participant 2).

I've watched the biggest and hardest people bottle it all up, being the big macho man and end up in psychiatric wards. I can think of one person who took his own life. (Participant 3).

It is clear from the preceding accounts that police culture inhibits emotional expression, often perpetuating the stigma associated with help-seeking for psychological distress (Tuckey et al. 2012), or for fear of stigma and discrimination from colleagues (Waugh et al. 2017).

\section{Subtheme 1.3: Coping Strategies}

When subjected to increased levels of stress, some officers will often resort to self-medication with alcohol as a coping mechanism. (Bell and Eski 2016) A small number of participants indicated that alcohol was something they used to help them cope with the pressures of work and psychological symptoms. One participant explained that he was so stressed and full of adrenalin; the insomnia he suffered prevented him from sleeping, and so he resorted to increased alcohol intake as a coping strategy.

You can't put enough adrenalin into your body to counteract the stress; you develop bad habits like drinking because it was the only way I could get to sleep and then you physically and mentally push yourself to the edge. (Participant 1).

Another interviewee commented she had started drinking to counteract the stress she was under.

... I'd started relying on alcohol... I'd started using alcohol as a coping mechanism. (Participant 5). 
While not all participants used alcohol, another noted he was aware of the drinking culture in some areas of policing; feeling obliged to drink to get ahead, which he saw as another added stressor.

...generally, if you want promotion you need to go in CID [Criminal Investigation

Department], a big drinking culture which I'm very averse to. (Participant 4).

Drinking alcohol is consistent with the need for police officers to maintain a certain image (Karaffa and Koch 2015; Shane and Andreychak 2008) and has been historically used to numb depressive feelings. Research has identified a link between problematic alcohol intake and higher levels of depression and anxiety in police officers (Karaffa and Koch 2015).

\section{Theme 2: Stigma of Mental Health}

Participants reported the adverse outcomes of developing mental illness whilst working within law enforcement. Responses included stigmatising attitudes and discrimination, self-stigma and lack of empathy.

\section{Subtheme 2.1: Stigmatising Attitudes and Discrimination}

Mental illness stigma in the police force is embedded at an individual and institutional level (Bullock and Garland 2018). A culture where the perception of mental illness plays a pivotal role in an individual's reaction to stress. Almost all participants experienced some form of stigma and conceded that mental illness is often viewed negatively by colleagues.

Some people that I spoke to when it happened were very negative because obviously there's a stigma with it. (Participant 1).

The success of one's career may well be negatively affected by mental health misconceptions. Many will experience challenges establishing a stigma-free relationship with their employers, whose opinion of the individual's ability to undertake their role may change (Gabriel and Liimatainen 2000). One officer argued, however, that his understanding was that attitudes in the police force were less stigmatising than in the private sector.

If anything, I would argue there's probably less stigma in organisations like the police than there is in most of the private sector. (Participant 3).

In contrast, a mental health charity, Mind (2017) states a higher prevalence of mental health problems has been found in the public sector, with a lack of support available following disclosure. This contrast may imply underestimation of mental health issues, linking with repressive coping (i.e., unconsciously deny negative emotions and information to secure a positive image (Garssen, 2007) that is often seen in a masculine culture (Kotera, Green \& Sheffield, 2019)).

\section{Subtheme 2.2: Self-Stigma}

Self-stigma occurs when individuals become aware of the societal stereotypes of people with mental illness and internaliase those attitudes (Stuart 2004). Individuals who are self-critical will often experience adverse emotional reactions such as feelings of low self-esteem and selfefficacy (Johnson 2016). The female participant began to display feelings of paranoia, thinking those around her disliked her. 
I was paranoid, part of my anxiety was paranoia, so I thought that everybody hated me, I still get that sometimes now. You can get really worked up about what other people think about you. (Participant 5).

Yet, she did feel the negativity she was experiencing was 'perceived and might not have been what was happening.' This internalised prejudice makes the individual affirm negative stereotypes of themselves because of their condition. The result of internalising public preconceptions of mental illness brought on by feelings of self-stigma creates negative feelings of frustration, anger and shame (Johnson 2016), as described by another participant when speaking about his visit to a counsellor.

Every time I spoke to her I burst into tears, it was a mixture of frustration, anger and shame. Shame that I'd gone pop, shame that I thought I'd let myself down. (Participant 3).

In summary, self-stigmatisation among police officers is considered a barrier to help-seeking behaviour, treatment adherence and recovery (Büchter and Messer 2017; Soomro and Yanos 2018).

\section{Subtheme 2.3: Lack of Support from Line Management}

Previous research has established that exposure to stressors such as increased workload and lack of organisational support can account for more significant amounts of stress in the police force than operational stressors (Shane and Andreychak 2008; Van Der Velden et al. 2013). Speaking with others, acts as an emotion-focussed coping strategy which aids in reducing occupational stress but also alters the way you react to stressful situations (Patterson 2003). In response to the question of what the police must deal with on a day-to-day basis, a retired officer expressed the need for support from others through talking.

I think it's the inability to say; actually, I've been affected by this, and someone to say, you know what, I'm affected by it as well, it's really bad isn't it. (Participant 4).

Lack of support and increased workload from senior managers are seen as significant predictors of mental health problems (Van Der Velden et al. 2013), thereby causing long-term absence and exacerbating already apparent psychological problems (Hayday et al. 2007).

In the end what tipped me over the edge, and I think it was building for a long time was a lack of support from senior managers. (Participant 5).

Although there were no outward signs the female participant was suffering from mental ill health, she felt her senior managers could have done more for her. She was on the brink of a 'meltdown', but she had no support; either senior managers did not recognise the signs or were unsure of how to deal with the situation.

I was very clearly on the brink, that somebody should have realised that. And I think they probably did; they just did not do anything about it. (Participant 5).

It is essential to recognise signs of mental illness in an employee but also to provide them with the opportunity to talk about how they feel without the risk of encountering negativity. 


\section{Theme 3: Disclosing Mental Illness}

One way of challenging the stigma of mental health is by revealing you are struggling (Corrigan and Rao 2012). However, disclosing to your employer that you have a mental health condition requires careful consideration after weighing up the pros and cons. Table 1 lists some of the advantages and disadvantages of disclosing a mental health condition (Wheat et al. 2010).

\section{Subtheme 3.1: Effect of Mental Illness on Career Advancement}

Officers who have mental ill health are frequently marginalised in the profession due to their reluctance to disclosure mental illness, thereby impacting their psychological wellbeing and career opportunities (Bell and Eski 2016). One participant stated that any form of mental illness would hinder career progression.

If you've a form of mental health illness you will not get on; you will not be promoted, ...people will not want you on their section. (Participant 4).

He went onto describe the perception of colleagues towards mental ill health.

My experience is the attitude of officers universally that I worked with. Depressed, depressed are timewasters. (Participant 4).

\section{Subtheme 3.2: Relationship with Fellow Officers}

Another participant who received a much more positive response from his division explained his fellow colleagues knew he could still be relied upon to perform his role as an officer. It was the less experienced, younger members of his team who were shocked to see someone with so many years' experience in the police fall foul to mental ill health.

He's been here for donkey's years, he should be able to handle this sort of thing...and then suddenly to watch me go pop. (Participant 3).

\section{Subtheme 3.3: Attitudes towards Sickness Absence}

Work stress, including shift work (Shane and Andreychak 2008), is the leading cause of sickness absence, ill health and early retirement of police officers (Garbarino et al. 2013; Hargreaves et al. 2018; Summerfield 2011). One participant recounted, even though there was

Table 1 Advantages and disadvantages of disclosing a mental illness

\begin{tabular}{|c|c|}
\hline Advantages & Disadvantages \\
\hline Enables the individual to receive support & Fear of stigma \\
\hline May lead others to disclose their conditions & May feel discriminated \\
\hline $\begin{array}{l}\text { Provides education of mental health conditions } \\
\text { to others in the workplace }\end{array}$ & May affect career prospects \\
\hline Employers may provide reasonable adjustments & Individual may feel undervalued \\
\hline Changes people's attitudes towards mental illness & $\begin{array}{l}\text { Places more focus on the condition } \\
\text { than the ability to perform in the job role }\end{array}$ \\
\hline Helps employees to identify changes in mood and behaviour & Job application may be rejected \\
\hline
\end{tabular}


support from occupational health, upon returning to work any reference to stress or depression was negatively viewed by fellow officers.

As an institution, they were very very good, in getting me better, at making me understand, but back at work that was a different ball game. You've got your colleagues who are still at work, still running around like idiots and they're like, oh fucking hell, you've had three months off, you know, I should have gone off with stress. (Participant 1).

It was obvious sickness absence had on the whole been viewed negatively. In contrast, one participant said he had been fairly treated by his line management because of his openness about his situation.

It's down to individuals. I've been in the job a long time, and I did know most people, most people did know my history, and those that didn't could read it. I got looked after really, I was just open and honest with them, I didn't try and big anything up, a lot of people gild the lily I suppose. Sort of just play straight baton, they looked after me. (Participant 2).

Senior managers acknowledged that the nature of his work affected his psychological wellbeing.

...we're gonna keep paying, realise it's job-related PTSD that you've got, so they made special dispensation that I'd be paid, I'd get a full wage. (Participant 2).

Despite the contrasting views on how sickness absence was viewed, it is important for line management to work with their staff to help reduce periods of sickness absence.

\section{Subtheme 4: Breaking Down Barriers}

Death by suicide occurs more in police officers than it does in the line of duty (Miller 2005). This is often due to the compounded stress experienced by police correlated with high rates of suicide (Collins and Gibbs 2003; Fox et al. 2012; Gutshall et al. 2017).

\section{Subtheme 4.1: Support from within the Force}

While most participants experienced difficulties with support from their line managers, all participants were provided with support through occupational health services; in the form of counselling, cognitive behavioural therapy (CBT), eye movement desensitisation and reprocessing (EMDR) therapy. Participants explained the benefits of referral to occupational health.

The welfare side was very very good, very quick. (Participant 1 ).

Although the time to referral was swift, one retired officer talked about the unsatisfactory initial meeting he had with an occupational health professional, as he was in such a vulnerable position at the time, he was experiencing negative thought patterns about health professions, who, in his words 'not having a clue what's going on'.

If you're in a very vulnerable position which I was, the slightest thing is too much, your thought pattern is already distorted. (Participant 4). 
Occupational health is seen as an avenue where individuals can disclose their mental health without fear of stigma. Despite the initial negative experience with counselling services, this officer did continue with his counselling sessions.

I went through extensive counselling, and for somebody to say what you're thinking, it requires a certain confidence, faith in the individual you're talking to, and a release of unburdening yourself from your own private thoughts. I don't think a lot of people can do that. (Participant 4).

One interviewee explained she had asked to be referred to occupational health because she felt she needed support but had not received any from her superiors. Her line manager admitted he recognised he was part of the problem and acknowledged that her mental health symptoms were exacerbated following a staffing incident which had occurred 12 months previously.

I was referred to occi health by my then line manager, well I asked him to refer me to occi health. (Participant 5).

There is a need for officers to seek help from psychological services. However, there still remains a gap between acknowledging this need and a call to action (Johnson 2016). A willingness to speak with others in a supportive environment is critical in help-seeking behaviour (Heffren and Hausdorf 2016).

You would find increasingly as my career progressed was that people would be more open in talking about these things. There was no sort of hiding it. (Participant 3).

\section{Subtheme 4.2: Increasing Education and Awareness}

Mental health awareness is determined mainly by perceptions of mental illness in society. It is affected by a range of social and cultural factors which also impact self-confidence and selfidentity. Stigmatisation and lack of knowledge of mental illnesses are critical considerations for improving awareness.

Oh, I think there was a lack of awareness because I remember a civilian member of staff, really nice guy and he used to go on about sickness levels, and he'd go, ah these malingers, "Stress? So and so's off with stress, it's malingering, it's malingering!" $\mathrm{He}$ used to go on about it. (Participant 4).

Using the analogy of having a broken leg was the participant's way of describing the lack of awareness and understanding which he experienced. Because you can see the physical injury to a person's leg, it proves the injury exists. However, with the mind, there are no visible signs of psychological injury.

The best way to describe it is if you've broken your leg and you've got a caste on, you can see that. (Participant 1).

\section{Subtheme 4.3: Changing Attitudes}

One interviewee described how his attitude changed as a result of going through mental ill health. He saw it as positive experience, helping to increase his mental health awareness and understanding. 
It has made me much much stronger and much more resilient, and the other thing is, I can see stress in other people. To be fair, I'm really glad I went through it because I've totally changed my outlook, I've totally changed the way I work, the way I look at everything in life. A very positive experience to go through, even though at the time it didn't feel like it. (Participant 1).

Likewise, another officer commented he had seen a noticeable difference in the way line management's attitudes were also changing.

...the police are trying to do more, I think they are trying to recognise signs of stress in people, and what have you, that's what they're training line managers to do anyway, they are putting us on courses about stress management and things like that. (Participant 5).

It is important that line managers are trained on how to identify the symptoms of mental ill health and help to reduce the psychological distress for officers (Bell and Eski 2016) if we want these attitudes to continue changing. Increasing awareness is important in order to spot the signs of mental illness. It is also important for fellow colleagues to recognise the signs.

Lived experience of mental ill health gives one the ability to identify the signs in others.

It's only because I've been through the process myself that you're able to recognise and assist with certain stuff. (Participant 1).

The psychosocial context of frontline police work has played a crucial role in the development and progression of mental illness, whether inflicted by traumatic experiences or by the more common pathway to psychological injury (Tuckey et al. 2012).

\section{Discussion}

The present study elucidated the first-hand experience of police officers' attitudes towards mental health problems, relating to the police culture. Five participants reported that the police culture was indeed affecting negative attitudes towards mental health problems (Theme 1), entailing mental health stigma (Theme 2), which hindered police workers to disclose their mental distress (Theme 3). Lastly, they suggested the ways to counter these challenges including a supportive workplace atmosphere and education (Theme 4).

One notable finding was that, as reported recently (Stuart 2017), police culture has a significant effect on attitudes to help-seeking behaviour and emotional responses to psychological distress. Any display of emotional response to work stress in police officers can be considered as a sign of weakness or inability to perform their role and goes against being tough, aggressive and in control (Kurtz 2008). Officers are therefore expected to maintain emotional self-control. Police culture is often thought of as a problematic feature of policing, which is averse to change and progress (Cordner 2017). This 'cult of masculinity' and 'machoism' is not only viewed as negative and persistent features of policing (Silvestri 2017) but also in other occupational groups such as the construction industry (Fielden et al. 2000), and the military (Karaffa and Koch 2015), which is typically male-dominant. It is interesting to note male dominance and gender featured greatly in a review of the literature (Fielden et al. 2000; Silvestri 2017; Veldman et al. 2017). Further research into this area could address these barriers.

The theme 'the stigma of mental health' represents feelings of discrimination towards mental illness experienced by some of the participants. The negative perception held by others 
towards them tended to be discriminatory in nature. Attitudinal barriers such as self-stigma were expressed and associated with feelings of shame, anger, frustration and paranoia (Gabriel and Liimatainen 2000). Some participants identified the negativity they faced from fellow officers and senior management. The effects of police-to-police mental illness-related stigma (Stuart 2017), self-stigma and perceived stigma were also apparent throughout the dataset. All participants conceded that colleagues negatively viewed mental illness. Moreover, consistent with previous literature (Maguen et al. 2009; Van Der Velden et al. 2010), depression, anxiety, PTSD and stress were among the main reasons for sickness absence among the interviewees (Harnois and Gabriel 2000; Husain 2014). Participants additionally reported that alcohol was frequently used as a coping mechanism. Further, police culture expects officers to remain calm and controlled; therefore, any emotional expression is severely limited (Pogrebin and Poole 1991), making difficult for officers to disclose their mental distress. As suggested, mental health awareness and understanding in the workplace and education about mental health could break down the barriers for officers to receive support. Moreover, training and development can help ameliorate the mental health status of police workforce. For example, induction training that informs the daily challenges and demands of the police profession would be useful for new officers to better prepare for various challenges that they may encounter during their duties (Gershon et al. 2009). Even though mental health is an essential factor of day-today policing, particularly in the community, it is an area which has been somewhat neglected (Cummings and Jones 2010). Future research should evaluate the effects of such training and development on the mental health attitudes of police workers, and their mental health status. Considering that poor mental health of police forces is a cause for concern in many other countries, more comprehensive studies (e.g., cross-cultural comparison) can offer useful insights to this international problem.

\section{Limitations}

There were several limitations in this study. Although a thematic analysis did not aim for generalisability, the sample size was modest: more data would strengthen our findings. Relatedly, only one participant was female. Other demographic variables that are associated with mental health and stigma (e.g. age, position, cultural background; Kotera et al. 2018a) needed to be adjusted. Notwithstanding the relatively limited sample, this work offers valuable insights into the culture of policing and the mental health of its officers.

\section{Conclusion}

The present study sought to elicit experiences from a sample of five police officers. The findings from this study indicate that sources of psychological illness have more to do with the organisational culture and attitudes to mental health than the nature of the job itself. The findings presented above highlight the need to increase mental health awareness in the British police force and to target institutional stigma, which is fundamental to breaking down attitudinal barriers. As sickness absence continues to rise due additional pressures put on officers, like budget cuts, fewer officers and increased crime, it is vital for police forces to recognise the signs of mental illness in their officers. Officers of all ranks must undergo education and implement changes in working practices to help reduce symptoms of psychological distress among its officers. 


\section{Compliance with Ethical Standards}

Conflict of Interest The authors declare that they have no conflict of interest.

Informed Consent All procedures followed were in accordance with the ethical standards of the responsible committee on human experimentation (institutional and national) and with the Helsinki Declaration of 1975, as revised in 2000 (5). Informed consent was obtained from all patients for being included in the study.

\section{Appendix 1. Participant Demographic Information}

\begin{tabular}{llllllll}
\hline Participant No & Gender & Age Ethnicity & $\begin{array}{l}\text { Marital } \\
\text { status }\end{array}$ & $\begin{array}{l}\text { Number of Rank } \\
\text { years in } \\
\text { Policing }\end{array}$ & $\begin{array}{l}\text { Current employment } \\
\text { status }\end{array}$ \\
\hline Participant 1 & Male & 43 & White British & Married & 18 & Police Sergeant \\
Participant 2 & Male & 52 & British & Married & 27 & $\begin{array}{l}\text { Serving officer } \\
\text { Patrol, Crime, } \\
\text { Training, }\end{array}$ & Retired (2 years) \\
& & & & & & Multi-Agency & \\
Participant 3 & Male & 56 & White British & Married & 30 & Police Constable & Serving officer \\
Participant 4 & Male & 62 & White British & Single & 24 & Police Sergeant & Retired \\
Participant 5 & Female & 48 & White British & Divorced & 22.5 & Police Sergeant & Serving officer \\
\hline
\end{tabular}

\section{Appendix 2. The Proposed Semi-structured Interview Schedule}

\section{Appendix 3. List of Key Themes and Subthemes}

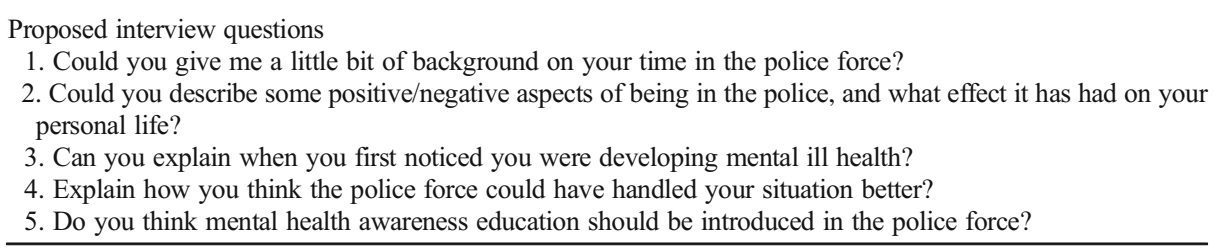

\begin{tabular}{|c|c|c|c|}
\hline Police culture & $\begin{array}{l}\text { The stigma of mental } \\
\text { health }\end{array}$ & Disclosing mental illness & $\begin{array}{l}\text { Breaking down } \\
\text { barriers }\end{array}$ \\
\hline - Macho culture & $\begin{array}{l}\text { - Stigmatising attitudes } \\
\text { and discrimination }\end{array}$ & $\begin{array}{l}\text { - Effect of mental illness on } \\
\text { career advancement }\end{array}$ & $\begin{array}{l}\text { - Support from within } \\
\text { the force }\end{array}$ \\
\hline $\begin{array}{l}\text { - Emotional response is a } \\
\text { sign of weakness }\end{array}$ & - Self-stigma & $\begin{array}{l}\text { - Relationship with fellow } \\
\text { officers }\end{array}$ & - Breaking the silence \\
\hline - Coping strategies & $\begin{array}{l}\text { - Lack of support from } \\
\text { line management }\end{array}$ & $\begin{array}{l}\text { - Sickness absence } \\
\text { procedures }\end{array}$ & $\begin{array}{l}\text { - Increasing education } \\
\text { and awareness }\end{array}$ \\
\hline
\end{tabular}


Open Access This article is licensed under a Creative Commons Attribution 4.0 International License, which permits use, sharing, adaptation, distribution and reproduction in any medium or format, as long as you give appropriate credit to the original author(s) and the source, provide a link to the Creative Commons licence, and indicate if changes were made. The images or other third party material in this article are included in the article's Creative Commons licence, unless indicated otherwise in a credit line to the material. If material is not included in the article's Creative Commons licence and your intended use is not permitted by statutory regulation or exceeds the permitted use, you will need to obtain permission directly from the copyright holder. To view a copy of this licence, visit http://creativecommons.org/licenses/by/4.0/.

\section{References}

Alexopoulos, E. C., Palatsidi, V., Tigani, X., \& Darviri, C. (2014). Exploring stress levels, job satisfaction, and quality of life in a sample of police officers in Greece. Safety and Health at Work, 5(4), 210-215.

Bell, S., \& Eski, Y. (2016). 'Break a leg —it's all in the mind': police officers' attitudes towards colleagues with mental health issues. Policing, 10(2), 95-101.

Booth, A., Scantlebury, A., Hughes-Morley, A., Mitchell, N., Wright, K., Scott, W., \& McDaid, C. (2017). Mental health training programmes for non-mental health trained professionals coming into contact with people with mental ill health: a systematic review of effectiveness. BMC Psychiatry, 17(1), 196. https://doi. org/10.1186/s12888-017-1356-5.

Braun, V., \& Clarke, V. (2006). Using thematic analysis in psychology. Qualitative Research in Psychology, 3(2), 77-101. https://doi.org/10.1191/1478088706qp063oa.

Büchter, R. B., \& Messer, M. (2017). Interventionen zur Reduktion der Selbststigmatisierung von Menschen mit psychischen Erkrankungen: Eine systematische Übersicht von randomisiert-kontrollierten Studien. GMS German Medical Science, 15, Doc07.

Bullock, K., \& Garland, J. (2018). Police officers, mental (ill-)health and spoiled identity. Criminology \& Criminal Justice, 18(2), 173-189.

Burke, R. J. (1998). Work and non-work stressors and well-being among police officers: the role of coping. Anxiety, Stress and Coping, 11, 345-362.

Carleton, N. R., Afifi, T. O., Turner, S., Taillieu, T., LeBouthillier, D. M., Duranceau, S., et al. (2018). Suicidal ideation, plans, and attempts among public safety personnel in Canada. Canadian Psychology, 59(3), 220231. https://doi.org/10.1037/cap0000136.

Clarke, V., \& Braun, V. (2018). Using thematic analysis in counselling and psychotherapy research: a critical reflection. Counselling and Psychotherapy Research, 18(2), 107-110. https://doi.org/10.1002/capr.12165.

Collins, P. A., \& Gibbs, A. C. C. (2003). Stress in police officers: a study of the origins, prevalence and severity of stress-related symptoms within a county police force. Occupational Medicine, 53(4), 256-264.

Cordner, G. (2017). Police culture: Individual and organizational differences in police officer perspectives. Policing, 40(1), 11-25.

Corrigan, P. W., \& Rao, D. (2012). On the self-stigma of mental illness: stages, disclosure, and strategies for change defining self-stigma. In Canadian Journal of Psychiatry (Vol. 57).

Cummings, I., \& Jones, S. (2010). Blue remembered skills: mental health awareness training for police officers. Journal of Adult Protection, 12(3), 14-19.

Deschamps, F., Paganon-Badinier, I., Marchand, A. C., \& Merle, C. (2003). Sources and assessment of occupational stress in the police. Journal of Occupational Health, 45(6), 358-364.

Deschênes, A.-A., Desjardins, C., \& Dussault, M. (2018). Psychosocial factors linked to the occupational psychological health of police officers: preliminary study. Cogent Psychology, 5(1), 1426271.

Desmarais, S. L., Livingston, J. D., Greaves, C. L., Johnson, K. L., \& Brink, J. (2014). Police perceptions and contact among people with mental illnesses: comparisons with a general population survey. Psychology, Public Policy, and Law, 20(4), 431-442.

Evans, R., Pistrang, N., \& Billings, J. (2013). Police officers' experiences of supportive and unsupportive social interactions following traumatic incidents. European Journal of Psychotraumatology, 4(SUPPL). https://doi. org/10.3402/ejpt.v4i0.19696.

Fielden, S. L., Davidson, M. J., Gale, A. W., \& Davey, C. L. (2000). Women in construction: the untapped resource. Construction Management and Economics, 18(1), 113-121. https://doi.org/10.1080 $/ 014461900371004$.

Fox, J., Desai, M. M., Britten, K., Lucas, G., Luneau, R., \& Rosenthal, M. S. (2012). Mental-health conditions, barriers to care, and productivity loss among officers in an urban police department. Connecticut Medicine, 76(9), 525-531.

Gabriel, P., \& Liimatainen, M. R. (2000). Mental health in the workplace: introduction, Executive Summaries. 
Garbarino, S., Cuomo, G., Chiorri, C., \& Magnavita, N. (2013). Association of work-related stress with mental health problems in a special police force unit. BMJ Open, 3(7).

Garssen, B. (2007). Repression: finding our way in the maze of concepts. Journal of behavioral medicine, 30(6), 471-481.

Gershon, R. R. M., Barocas, B., Canton, A. N., Li, X., \& Vlahov, D. (2009). Mental, physical, and behavioral outcomes associated with perceived work stress in police officers. Criminal Justice and Behavior, 36(3), 275-289.

Gutshall, C. L., Hampton, D. P., Sebetan, I. M., Stein, P. C., \& Broxtermann, T. J. (2017). The effects of occupational stress on cognitive performance in police officers. Police Practice and Research, 18(5), 463-477.

Habersaat, S. A., Geiger, A. M., Abdellaoui, S., \& Wolf, J. M. (2015). Health in police officers: Role of risk factor clusters and police divisions. Social Science and Medicine, 143, 213-222. https://doi.org/10.1016/j. socscimed.2015.08.043.

Hargreaves, J., Husband, H., \& Linehan, C. (2018). Police workforce, England and Wales, 31 March 2018. Statistical Bulletin, 11(18).

Harman, G. (2019). Answering the call: mental health needs of police and emergency services personnel. Australian Journal of Emergency Management, 34(1), 23 Retrieved from www.beyondblue.org.au/.

Harnois, G., \& Gabriel, P. (2000). Mental health and work: impact, issues and good practices. Retrieved from http://digitalcommons.ilr.cornell.edu/gladnetcollect/222/.

Hayday, S., Broughton, A., \& Tyers, C. (2007). Managing sickness absence in the police service: a review of current practices. London: HSE.

Heffren, C. D. J., \& Hausdorf, P. A. (2016). Post-traumatic effects in policing: perceptions, stigmas and help seeking behaviours. Police Practice and Research, 17(5), 420-433.

Houdmont, J. \& Elliott-Davies, M. (2016). Police Federation of England and Wales 2016 Officer Demand, Capacity, and Welfare Survey: Initial Report -Descriptive Results

Husain, W. (2014). The levels of depression, anxiety and stress in police officers. Academic Research International, 5(4).

Johnson, S. F. (2016). Investigating Barriers to Mental Health Care in Law Enforcement Officers. Electronic Theses and Dissertations. Paper 3154. https://dc.etsu.edu/etd/3154

Karaffa, K. M., \& Koch, J. M. (2015). Stigma, pluralistic ignorance, and attitudes toward seeking mental health services among police officers. Criminal Justice and Behavior, 43(6), 759-777.

Kotera, Y., Adhikari, P., \& Van Gordon, W. (2018a). Motivation types and mental health of UK hospitality workers. International Journal of Mental Health and Addiction, 16(3), 751-763. https://doi.org/10.1007 /s11469-018-9874-z.

Kotera, Y., Green, P., \& Sheffield, D. (2018b). Mental health attitudes, self-Criticism, compassion and role identity among UK Social Work Students. The British Journal of Social Work, 49(2), 351-370.

Kotera, Y., \& Ting, S. H. (2019). Positive Psychology of Malaysian University Students: Impacts of Engagement, Motivation, Self-Compassion, and Well-being on Mental Health. International Journal of Mental Health and Addiction, 1-13.

Kotera, Y. , Green, P. , and Sheffield, D. (2019). Mental Health Shame of UK Construction Workers: Relationship with Masculinity, Work Motivation, and Self-Compassion. Journal of Work and Organizational Psychology, 35(2), 135-143. https://doi.org/10.5093/jwop2019a15

Kurtz, D. L. (2008). Controlled burn: the gendering of stress and burnout in modern policing. Feminist Criminology, 3(3), 216-238.

Lamb, H. R., Weinberger, L. E., \& DeCuir, W. J. (2002). The police and mental health. Psychiatric Services, 53(10), 1266-1271.

LaMontagne, A. D., Martin, A., Page, K. M., Reavley, N. J., Noblet, A. J., Milner, A. J., et al. (2014). Workplace mental health: developing an integrated intervention approach. BMC Psychiatry, 14(1), 131.

Liberman, A. M., Best, S. R., Metzler, T. J., Fagan, J. A., Weiss, D. S., \& Marmar, C. R. (2002). Routine occupational stress and psychological distress in police. Policing, 25(2), 421-441.

Link, B. G., Cullen, F. T., Struening, E., Shrout, P. E., Dohrenwend, P., Link, B. G., et al. (1989). A modified labeling theory approach to mental disorders : an empirical assessment. American Sociological Association, 54(3), 400-423.

Maguen, S., Metzler, T. J., McCaslin, S. E., Inslicht, S. S., Henn-Haase, C., Neylan, T. C., \& Marmar, C. R. (2009). Routine work environment stress and PTSD symptoms in police officers. Journal of Nervous and Mental Disease, 197(10), 754-760.

Marchand, A., Nadeau, C., Beaulieu-Prévost, D., Boyer, R., \& Martin, M. (2015). Predictors of posttraumatic stress disorder among police officers: a prospective study. Psychological Trauma: Theory, Research, Practice, and Policy, 7(3), 212-221.

Markowitz, F. E. (2014). Mental Illness and Labeling Theory. The Wiley Blackwell Encyclopedia of Health, Illness, Behavior, and Society, (December 2013), 1582-1587. https://doi.org/10.1002/9781118410868.wbehibs328.

Marmar, C. R., McCaslin, S. E., Metzler, T. J., Best, S., Weiss, D. S., Fagan, J., ... Neylan, T. (2006). Predictors of posttraumatic stress in police and other first responders. Annals of the New York Academy of Sciences, 1071(1), 1-18. 
Miller, L. (2005). Police officer suicide: causes, prevention, and practical intervention strategies. International Journal of Emergency Mental Health, 7(2), 101.

Mind. (2013). Mental wellbeing - Police $\mid$ Mind, the mental health charity - help for mental health problems. Retrieved from https:/www.mind.org.uk/information-support/police/mental-wellbeing-police/\#.W-R_tdL7 Tcs.

Mind. (2017). Mind reveals shocking differences in mental health support for public \& private sector workers. Retrieved from https://www.mind.org.uk/news-campaigns/news/mind-reveals-shocking-differences-inmental-health-support-for-public-private-sector-workers/

Morash, M., Haarr, R., \& Kwak, D. H. (2006). Multilevel influences on police stress. Journal of Contemporary Criminal Justice, 22(1), 26-43.

Myhill, A., \& Quinton, P. (2011). It's a fair cop? Police legitimacy, public cooperation, and crime reduction An interpretative evidence commentary. Retrieved from http://whatworks.college.police. uk/Research/Documents/Fair_cop_Full_Report.pdf .

Nowell, L. S., Norris, J. M., White, D. E., \& Moules, N. J. (2017). Thematic analysis: Striving to meet the trustworthiness criteria. International Journal of Qualitative Methods, 16(1), 1-13. https://doi.org/10.1177/1609406917733847.

Office for National Statistics. (2017). Sickness absence in the UK labour market - Office for National Statistics. Retrieved from https://www.ons.gov.uk/employmentandlabourmarket/peopleinwork/labour productivity/articles/sicknessabsenceinthelabourmarket/2016 .

Patterson, G. T. (2003). Examining the effects of coping and social support on work and life stress among police officers. Journal of Criminal Justice, 31(3), 215-226.

Pogrebin, M. R., \& Poole, E. D. (1991). Police and tragic events: the management of emotions. Journal of Criminal Justice, 19(4), 395-403.

Police Federation of England and Wales. (2020). Mental Health. Retrieved 8 January 2020, from https://www. polfed.org/our-work/mental-health/

Police Firearms Officer Association. (2017). Police Mental Health sickness up by 47\% - The PFOA News feed. Retrieved from https://www.pfoa.co.uk/blog/police-mental-health-sickness-up-by-47.

Pols, H., \& Oak, S. (2007). The US psychiatric response in the 20th century. American Journal of Public Health, 97, 2132-2142.

Randall, C., \& Buys, N. (2013). Managing occupational stress injury in police services: a literature review. International Journal of Public Health, 5(4), 413-425 Retrieved from https://search.proquest. com/openview/8336a40d8692a2d359fdebf5f46cac82/1?pq-origsite=gscholar\&cbl=2034853.

Scheff, T. J. (1966). Being mentally ill: a sociological theory. Chicago: Aldine.

Shane, J., \& Andreychak, C. (2008). Organizational stressors and police performance. Conference Papers American Society of Criminology, 1.

Silvestri, M. (2017). Police culture and gender: revisiting the "cult of masculinity". Policing (Oxford), 11(3), 289-300. https://doi.org/10.1093/police/paw052.

Sofaer, S. (1999). Qualitative methods: what are they and why use them? Health Services Research, 34(5 Pt 2), 1101-1118. https://doi.org/10.1080/09638237.2017.1370635.

Soomro, S., \& Yanos, P. T. (2018). Predictors of mental health stigma among police officers: the role of trauma and PTSD. Journal of Police and Criminal Psychology, 1-9.

Stuart, H. (2004). Stigma and work. Healthcare Papers, 5(2), 100-111.

Stuart, H. (2017). Mental illness stigma expressed by police to police. Israel Journal of Psychiatry and Related Sciences, 54(1), 18-23.

Summerfield, D. (2011). First person: Metropolitan police blues: protracted sickness absence, ill health retirement, and the occupational psychiatrist. BMJ, 342. https://doi.org/10.1136/bmj.d2127.

The Centre for Addiction and Mental Health (CAMH). (2018). Police mental health : a discussion paper. (October), 1-14.

Thomas, S., Jenkins, R., Burch, T., Nasir, L. C., Fisher, B., Giotaki, G., ... Wright, F. (2016). Promoting mental health and preventing mental illness in general practice. London Journal of Primary Care, 8(1), 3-9.

Tuckey, M. R., Winwood, P. C., \& Dollard, M. F. (2012). Psychosocial culture and pathways to psychological injury within policing. Police Practice and Research, 13(3), 224-240.

Tuohy, A., Knussen, C., \& Wrennall, M. J. (2005). Effects of age on symptoms of anxiety and depression in a sample of retired police officers. Psychology and Aging, 20(2), 202-210.

Van Der Velden, P. G., Kleber, R. J., Grievink, L., \& Yzermans, J. C. (2010). Confrontations with aggression and mental health problems in police officers: the role of organizational stressors, life-events and previous mental health problems. Psychological Trauma: Theory, Research, Practice, and Policy, 2(2), 135-144.

Van Der Velden, P. G., Rademaker, A. R., Vermetten, E., Portengen, M. A., Yzermans, J. C., \& Grievink, L. (2013). Police officers: a high-risk group for the development of mental health disturbances? A cohort study. BMJ Open, 3(1).

Veldman, J., Meeussen, L., Van Laar, C., \& Phalet, K. (2017). Women (do not) belong here: Gender-work identity conflict among female police officers. Frontiers in Psychology, 8(FEB). https://doi.org/10.3389/fpsyg.2017.00130. 
Violanti, J. M., Fekedulegn, D., Hartley, T. A., Charles, L. E., Andrew, M. E., Ma, C. C., \& Burchfiel, C. M. (2016). Highly rated and most frequent stressors among police officers: gender differences. American Journal of Criminal Justice : AJCJ, 41(4), 645-662.

Watson, A. C., Swartz, J., Bohrman, C., Kriegel, L. S., \& Draine, J. (2014). Understanding how police officers think about mental/emotional disturbance calls. International Journal of Law and Psychiatry, 37(4), 351-358.

Waugh, W., Lethem, C., Sherring, S., \& Henderson, C. (2017). Exploring experiences of and attitudes towards mental illness and disclosure amongst health care professionals: a qualitative study. Journal of Mental Health, 26(5), 457-463. https://doi.org/10.1080/09638237.2017.1322184 .

Weller, S. C., Vickers, B., Russell Bernard, H., Blackburn, A. M., Borgatti, S., Gravlee, C. C., \& Johnson, J. C. (2018). Open-ended interview questions and saturation. PLoS One, 13(6), e0198606. https://doi.org/10.1371 /journal.pone.0198606.

Wester, S. R., Arndt, D., Sedivy, S. K., \& Arndt, L. (2010). Male police officers and stigma associated with counseling: the role of anticipated risks, anticipated benefits and gender role conflict. Psychology of Men and Masculinity, 11(4), 286-302.

Wheat, K., Brohan, E., Henderson, C., \& Thornicroft, G. (2010). Mental illness and the workplace: conceal or reveal? Journal of the Royal Society of Medicine, 103(3), 83-86.

Wood, J. D., Watson, A. C., \& Fulambarker, A. J. (2017). The "gray zone" of police work during mental health encounters: findings from an observational study in Chicago. Police Quarterly, 20(1), 81-105.

Publisher's Note Springer Nature remains neutral with regard to jurisdictional claims in published maps and institutional affiliations. 